\title{
Institutional Challenges and Economic Agents Forming a Competitive Market Environment
}

\author{
Kireeva-Karimova A.
}

Kazan Federal University, Institute of Management, Economics and Finance, Kazan, 420008, Russia

\section{Doi:10.5901/mjss.2015.v6n1s3p211}

\section{Abstract}

Enterprise (organization) as a slice of society on a global scale is the agent of a competitive market environment, selfproduction of which is the heart of its existence. Changes in the institutional environment and social values of the society have led to the convergence of historical organizational forms of enterprise: commercial and non-profit organizations, appearance of modern hybrid forms - environment serving organizations - ESO. They have the characteristics of active businesses and indifferent public organizations and institutions that are differentiated by the method of replenishment of financial resources. In a global economy there is also the transformation of the classical conception of the competition as a clash of opposing economic interests of agents to the antagonistic approach from the point of supercompetition - awareness of the effectiveness of alliances and cooperation of ESO. Integrated business groups - IBG: conglomerates of diversified ESO integrated as outsourced and virtual type of organization, financial industrial groups (FIGs), strategic network, successfully survive in a crisis. The research analyzed the conceptual model of the relationship between the government institutions of management, market structure of the competitive environment, the institutional challenges of ESO's environment and strategic decisions competitive traps (patterns) of IBG.

Keywords: economic agents, the convergence of historical organizational forms of business environment serving organizations ESO, supercompetition, sustainable development strategy - SDS, integrated business groups - IBG, diversification, integration in outsourced and virtual form, financial-industrial groups, a synergistic effect, a model of interdependence, government institutions of management, the market structure of the competitive environment, the institutional challenges of ESO's environment, strategic decisions and competitive trap, patterns of IBG.

\section{Introduction}

Enterprises and organizations form the behavior of economic agents (economic agents) which defines the basic characteristics of government. Like the society on a global scale, they are the only institutions among economic entities, self-production of that are laid down in the basic concept (base) of their existence, and the symbiosis of the state and enterprises are the only way of a successful mutual existence [10]. Almost every long going concern is a microscale model of the state. Its socio-economic status is related to socio-economic type of society and the state. Having entrenched in organizations, the following institutions as cooperation, discipline, obedience, leadership become decisive in the political life of the country also (put simply, notably the companies decide to pay taxes or not, pay salaries or delay, praise the authorities or defend independence). On the other hand, the activities of enterprises are affected by the entire institutional environment of the state and the macroeconomic environment factors (trend of growth (recession), the volume of industrial production, the dynamics of purchasing power of the ruble, the magnitude of unemployment, the tendency of the population to invest in corporate bonds, legal and economic discipline) which are functions of the indicators of economic agents, i.e. enterprises. The company, as such, is one of the main institutions of the organization of national production in the modern economy of Russia $[3,7]$.

In modern conditions of postindustrial economy classical differentiation of the enterprises on commercial with the assets belonging to the private capital, and non-profit ones, being in public, state and municipal property, does not meet the realities of the global economic environment. Businesses which effective and aggressively respond to the challenges of the competitive environment. Their integrated business groups and internal bureaucratic, inappropriate to market changes organizations and institutions, performing the functions of public consumption, have different material, financial sources of replenishment of its own resources. Commercial enterprises do it through commercial contracts and deals in the sale of the results of their own activities to various environment economic agents. The second ones, non-profit enterprises, do it through subsidies, transfers which made or provided by external agents without the requirement of their compensation in kind. Changing of social mechanisms, social priorities, and institutional environment have led to a 
convergence of historical organizational forms of enterprises (Fig. 1).

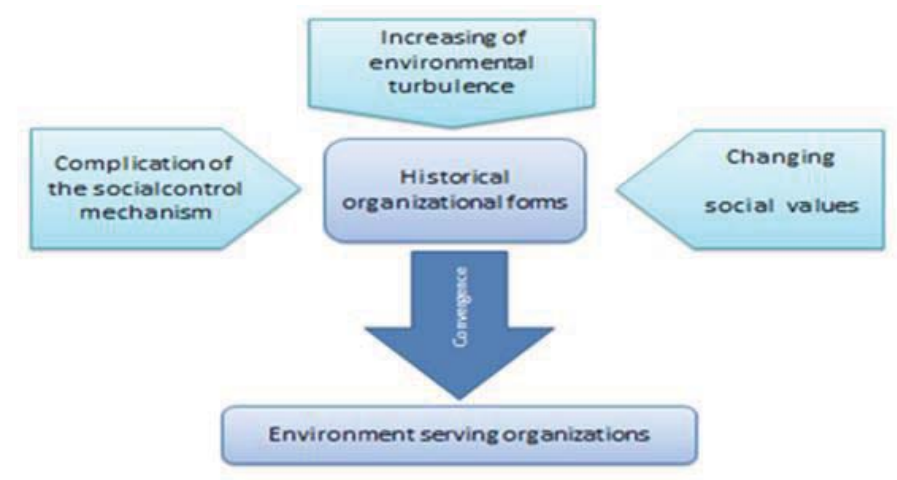

Fig. 1. Formation factors of ESO - environment serving organization

Public institutions (agencies, institutions, territorial offices, registration offices) have been involved in entrepreneurial activity, which previously was the exclusive domain of business structures, and a discriminatory behavior of private enterprises aimed at its own management utility have met growing public pressure to curb such organizational behavior leading to undesirable material and social consequences and violating ethical standards. These circumstances contributed to the fact that businesses entities focused solely on getting the target profit have assumed cost-based social obligations.

The public sector is under the influence of objectively growing need to really compete with the efficiency of commercial business structures through the creation of so-called intersecting organizations. Each of these organizations, according to Ansoff's terminology, a hybrid that has the features of private enterprise and the social structure [1]. These two types of organizations, as representatives of a single class, are called as organizations serving the needs of the environment - environment serving organization (ESO). The scope of their activities include the supply of goods and / or services to meet the community needs.

ESO class includes business structure, HEls (universities), hospitals, religious institutions, government-owned institutions (such as registration offices, post office), common licensing services, notariate. In modern society the majority of employees and public servants are engaged in such organizations. Both of these categories - the concept of "enterprise" and the term ESO - organization serving the needs of the environment are identical, though not identical to the full extent.

\section{Method}

At the same time, it is difficult to recognize a state of the vast majority of domestic organizations serving the environment of various forms of ownership and sectoral affiliation, and commercial businesses (more than 6 million of companies in 1400 various industries have been registered in 2014 in a single register of enterprises and organizations of all forms of ownership and business models) as satisfactory $[12,15]$. The practical use of strategic approaches to planning and management of ESO, the introduction of real economic activity of various economic agents of competitive and socially oriented market environment, the use of tools and methods of corporate sustainable development strategy - SDS will help to optimize their performance and efficiency of the formation of a convenient ("lean") environment.

Within the scope of the modern economic development the traditional attitude to the competition as a clash of interests opposing economic agents requires rethinking and revision. Canonical essence of competition has transformed into the concept of super (hyper) competition. According to V.S.Efremov, a well-known domestic expert in the field of strategic planning and management, in the context of hypercompetition, the cooperation, collaboration, strategic alliances are the only effective means of survival of the organization "Competition is a war, and start the war under the conditions of hypercompetition means to fight none of the above. One soldier does not make a battle"[5].

In a state of instability (cyclical crises in $1974-1975,1980-1982$, structural 90s, the global $2010-2014$ ), the concept of diversification as a variant of the historic business expansion had been widely applied [1,6]. In translation from Latin "diversification" means 'change, diversity'. At a standstill a perilous concentration "of all eggs in one basket", and without taking into account a proven approach of balancing set of "apples and oranges" in the business portfolio of the commercial enterprises and ESO made by the consulting company McKinsey \& Company may lead to the collapse of the 
organization $[9,14]$.

The problem of diversification is relevant nowadays as in the domestic and Western business practice it is quite widespread a point of view that in the current economic conditions the successful organization should be diversified, notably in many ways: with suppliers, markets, product range, types of activity $[1,6,13]$. Therefore Russian enterprises are jointed in holdings on the basis of vertical and horizontal integration, or by principle of foundation of conglomerates and/or strategic alliances, according to D. Lvov, integrated business groups - IBG [7]. The purpose of this alliance is to reduce risks and finding some balance in the context of increasing threats to unfavorable environment. Business associations in vertical and integrated corporates occur in the largest economy of the world, in the United States, too. However, there is the opposite tendency - split of large conglomerates [13].

In the economic literature it is customary to distinguish the related (vertical and horizontal) and unbound (conglomerate) diversification [6]. The task of related diversification is to provide additional competitive benefits, take advantage of the value chain of M. Porter for capitalization growth of organization, and flood of synergetic effect of sharing of marketing and research development according to R.Buzzel, B. Gale in order to minimize its cost $[8,17]$.

Related vertical diversification combines several technologically successive stages of production of goods as opposed to unification processes within a single step. This is achieved by acquisition or inclusion in the organization of new productions included in the processing chain of an existing product, which leads to the replacement of traditional market planning and management of modern forms of corporate management, as well as to establish a clear outlines between the production system and the market.

Horizontal diversification has the form of involvement in economic activities the technological business processes of ESO within a single field of activity (industry or group of industries with similar characteristics). It can be fulfilled by two ways: through in-house production of the related to the main product or incidental lines of products, or through the acquisition of existing enterprises-competitors. This diversification has a positive synergistic effect, but increases the vulnerability of organizations from turbulence environmental and discriminatory behavior of economic agents of the market (from threats of inner circle).

The related horizontal diversification contemplates penetration of the company in close areas of activity, somehow contacting with the current one in a single phase of production, instead of a few industries (so-called latent diversification). Thus, this type of diversification is based on strategic adequacy and gentility of separate layers of ESO with similar value chains.

The unbound (or conglomerate) diversification involves invasion of the organization in any unconventional spheres of activity and manufacturing of new products not coinciding with the traditional profile. In this case the units of organization haven't common markets, resources, and technology. Based on the financial approach, the object of such diversification is not production but financial capital. It pursues the aim of an effective investment of available funds and formation of venture, flexible corporate business portfolio.

The integration processes in a post-industrial economy caused by the growing hypercompetition. Integration (from Latin integratio - "connection") is the process of organizational unification of industrial enterprises, ESO, retailers following from the strategic objectives and tasks of sustainable development. The same term characterizes the association of elements of the production process and the funds of the organization, too. Thus, not only organizational, but also technological and financial side of integration are manifested $[3,6]$. $[4,5]$.

Currently the following types of integration of economic entities in integrated business groups can be distinguished

Insourcing (internal) type of integration implies that all activities related to the production and final product realization are carried out in a single IBG. As a result, all necessary for obtaining the final product is created within the association, and can't be bought on the side. The primary resources (energy, raw materials, fuel and so forth) are arriving from an external environment only, and thus, manufacturing is not only technically, but also the organizationally united. Consumers buy finished goods issued on the manufacturer's initiative without participating with their ideas and resources in its creation. As a result, this process is unidirectional one. Management of the entire complex is carried out by managers of the parent company, but the companies included in the association compete for centrally distributed general resources (mostly financial ones).

Insourcing type of productive integration is based on the related diversification strategies and financial on the unrelated ones, product development and market.

Outsourcing (external) type of integration is based on involving external companies to perform certain operations associated with the manufacture and marketing of products. Thus, the production is becoming open instead closed, and technological cooperation between the participants is converted into the functional one.

The products are manufactured both on the basis of a strategic plan for sustainable development and partly on the 
basis of contracts for which (not just for resources) between the enterprises there is a competition. The organizations decide the issues concerning the partners, volume and sequence of order processing independently.

The transition to a virtual method for the integration of the enterprises into the common business space and choice of the corresponding strategy are caused by the following:

- availability of the information infrastructure to collaborate virtually;

- compatibility of the internal organization and culture with information and technological infrastructure of common business space.

Associations on the basis of virtual integration allow the use of unique market opportunities that participants can't implement independently [5].

In choosing a method of vertical integration it is required to define the boundaries within which all business processes can be seen as the internal organization processes and beyond them - as external ones. The expansion of these boundaries entails greater concentration of production within the same organization, thereby increasing its presence in the industry as well as in the relevant market which leads to an increase of concentration rate (increase in the index of $\mathrm{CR}$ and $\mathrm{IHH}$ ) and the monopolization of the market.

Specific organizational form of integration processes is the Financial Industrial Group (FIG), whose members can be connected internally as follows: financial liabilities promoting a sustainable development; synthesis of industrial and banking cooperation; mutual exchange of equity stakes; long-term strategic and transfer contracts; regular meetings of the leaders; cross-membership in the directorates [7,3].

To achieve their goals, FIG should include both production and financial structures acting as a parent and its subsidiaries, either partially or fully having merged their assets on the basis of the contract. They fulfill economic or technological integration for the implementation of the investment programs or programs aimed at improving their competitiveness.

The need of creation of FIG is caused by the vital strategic necessity to overcome the crisis of economic restructuring, strengthening and updating process chains, facilitating access to the world markets.

The optimum combination of the participants in the group creates the rational terms for enhancing the stability of FIG (based on the convergence of strategic objectives and interests of united economic agents) and efficiency by means of the implementation of various forms of flexibility and synergy. Along with that the list of participants isn't permanent. It must be developed by complicating of the goals and tasks of the integrated system, in changing in environment, owing to lower efficiency of individual participants. Thus, from a position of potential participants, the structural composition of FIG should be considered as an important interactive parameter of the current and strategic planning by internal efficiency and external competitiveness.

In the context of innovation competition and restructured Russian economy it is extremely essential that FIG is able to expand investment opportunities of industrial companies at the expense of borrowed capital thanks to presence of stable shareholders and banks. Public shareholders as a part of FIG will allow boosting the rational structural shifts in production. Integration into FIG in compared with the merger into a single company will allow avoiding weakening of motivations of grouped companies, optimize their production scale and price competitiveness.

The high level of value added tax, the pressure on the ruble money supply in the framework of macroeconomic stabilization measures pushed Russian organizations and enterprises to integrate in the form of holdings and a single corporation. But the integration of several competing groups in each of the monopolized sectors of the Russian economy (engineering and defense industry, petrochemical, chemical, mining) in the framework of FIG will mean a transition from supermonopolism to oligopoly competition prevailing in the industrialized countries. Thus, widespread trend towards associations and holding companies that collect in their structure of the one-type production and thereby recreating the former monopoly industry would be destroyed.

Integration processes in the post-industrial economy lead to the formation of strategic networks. A network is a set of enterprises and their associations coordinated by market mechanisms, and the chain of command is replaced by a chain of orders.

Network development began in the late eighties due to the worsening international competition and actively is continuing today. The networks can join together suppliers and customers linked technologically and economically and interested in cooperation, and distributors of goods who can co-operate on the principles of a participatory, freedom of partners identifying and information exchange, trust and respect for ethic social norms [2].

\section{The Main Part}

The President of Russia V. Putin [11] aims society and the government that the large-scale changes in the reproductive 
structure of modern Russian economy, a significant improvement in the institutional environment of organizations which are necessary for their successful operation and harmonization with industrial and market-based policies, rapid elimination of disproportion caused by technological mixed economy can't be done by relying on market mechanisms of competition only. Analytical framework for the research of market processes can serve the cluster diagram of market structure, the behavior of the organization and functioning of the market that we recommend in this study (Fig. 2). It is known that the behavior of businesses and ESO are reflected in the structure and functioning of the market. In an effort of increasing their market share through mergers and acquisitions, they raise the level of market concentration, affect conditions of entry into the industry, and monopolizing it, change the market structure, which in turn, influences efficiency of functioning of the market, efficiency of distribution of resources at vertical integration, in the presence of the price pressure or arrangement at the horizontal can decrease at simultaneous increase of efficiency of their use in FPG and strategic networks (through the synergistic effect of a single administrative unit, joint storage of reserve stocks, discounts on bulk purchases, reducing the cost of capital, R \& D cooperation, the effect of the spill marketing). The functioning of this market affects its structure and the subsequent behavior of economic agents whose excess profits may encourage other organizations to enter the industry. It helps to lower the concentration, impacts on production efficiency and innovation and creates a driving force for the competitive environment.

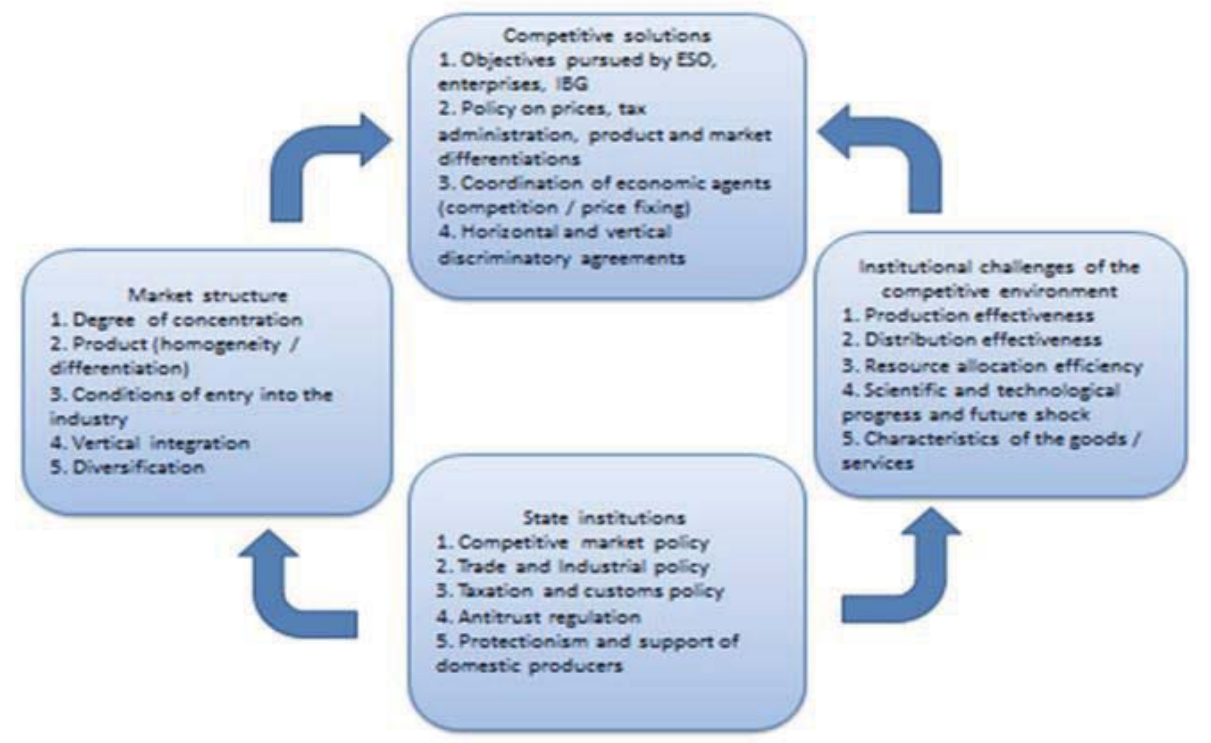

Fig. 2. Conceptual model of the relationship between state institutions, market structure, institutional challenges of the environment and competitive solutions organizations (IBG, enterprises, ESO).

Priorities for long-term development of the organization assign outlines of industrial policy and market of comprehensive system of SDS organizations. Transformation of marketing and logistics complex and Research and Advanced Development complex, strengthening or weakening their role in the organization reflect the direction of strategic changes of the latter. The need to differentiate their own products, develop of personalized methods of interaction with the end user increase the interest of economic agents to product management model (in the management practice of domestic manufacturers technology brand management are beginning to use).

Activation of market-based policy associated with large-scale reform of legislation at the turn of the centuries contributed to the establishment of stable relations between the major economic agents in the market, the emergence of new progressive institutions (FIG) and integrated business groups (IBG).

Comprehensive market imperfections are mainly caused by the state economic activity. Assuming part of loading on overcoming of imperfections of market economy and other barriers ('locking effects' on V.E.Dementiev's terminology [3]) of market coordination, FIG reduce appropriate loading on the state. Herewith they neutralize the locking effects, which characterize the state of coordination of economic activities, solving the problem of strategic resources maneuver between sectors and promoting the transfer of the developed and mature industries (step G-2 and M on Gompart's curve) to the category of donors of new strategic breakthrough.

Taking into account the above, it is represented to us that due to the insufficient level of competitiveness of many 
industries and the real sector's enterprises, their unavailability to function in the conditions of the World Trade Organization (WTO) speed up the joining processes would be premature. Russia's accession to the WTO predetermines, in particular, the harmonization of tariffs capable considerably to reduce price competitiveness of many domestic producers whose stocks have been exhausted.

\section{Results}

Intermittence, hardly predictability of changes of the competitive environment change traditional ideas of entrepreneurship, business, production, the commercial and social public work of agents of the market environment. The period of globalization of economy reoriented policy of confrontation of competing companies and organization on policy of cooperation and partnership of successfully surviving companies.

Multinational (multilocal) corporations and alliances, the integrated business groups become the main subjects of global economy. According to many modern researchers the economic pressure of globalization is inevitable, and it will lead to refusal of traditional views of an industrial and trade policy, the issues of post-industrial macro - and microeconomics, conditions of the competitive environment of the national and local markets, the trends and benchmarks for sustainable development.

\section{References}

Ansoff I. Strategic Management. The classic edition / Transl. from English. Ed. Petrov A.N. - SPb.: Piter, 2009.

Nagimova, A.M., Safiullina, F.R. (2014). Combination of university training with employment among Kazan' students. Sotsiologicheskie Issledovaniya, (4), pp. 121-124.

Grieve G. Rowley, T., Shepilov A. Advantage of networks: How to derive the maximum benefit from alliances and partnerships. - M .: Alpina Publisher, 2014.

Dementiev V.E. Rivalry for effect from the occupied market share as a factor of unevenness of economic development / Theory and practice of institutional transformations in Russia. Vol. 9. - M .: CEMI RAS, 2007.

Efremov V.S. Business strategy. Concepts and methods of planning: Textbook. - M .: Publishing house "Finpress", 1998.

Efremov V.S. Strategic planning in business systems. - M .: Publishing house "Finpress", 2001.

Zub A.T., Loktionov M.V. Strategic Management. A systematic approach. - M .: Genesis, 2011.

Lvov D. Institutional Economics. - M .: INFRA-M, 2001.

Tsertseil, J.S. The way of clusters uprising and development in the region (By the example of the petrochemical cluster in the republic of Tatarstan). Mediterranean Journal of Social Sciences, Volume 5, Issue 18 SPEC. ISSUE, 2014, Pages 125-128

Porter M. Competition: Trans. from English. - M .: Publishing house "Williams", 2010.

The method of McKinsey: the use of technology of leading strategic consultants for the solution of personal tasks and problems of your business / Trans. from English. - 2nd ed. - M .: Harvard Business Review, 2004.

Glazyev S.Y. No theory - no economy. - http://www.russiapost.su/archives/11319.

Safina, D., Podgornaya, A. (2014). Mobbing as an organizational phenomenon impeding implementation of changes. Mediterranean Journal of Social Sciences, 5 (18 SPEC. ISSUE), pp. 187-192.

Putin V. The report on the St. Petersburg International Economic Forum. - http://itar-tass.com/ekonomika/1210424.

Uniform federal register of information about the facts of legal entities. - http://www.fedresurs.ru/Companies; http://egrul.nalog.ru

Buzzel Robert D. and Gale Bradley T. The PIMS Principles: Linking Strategy to Performance. - The Tree Press, a division of Macmillan Inc., 1987. 